\title{
Odontometric analysis of sexual dimorphism in permanent maxillary and mandibular molars
}

\section{Kazzazi $\mathrm{SM}^{* 1}$ and Kranioti $\mathrm{EF}^{1,2}$}

${ }^{1}$ Edinburgh Unit for Forensic Anthropology, School of History Classics and Archaeology, University of Edinburgh, Edinburgh, United Kingdom

${ }^{2}$ Department of Medical Imaging, University Hospital of Heraklion, Heraklion, Greece

*Corresponding author: Kazzazi SM, Edinburgh Unit for Forensic Anthropology, School of History, Classics and Archaeology, University of Edinburgh, William Robertson Wing, Edinburgh, EH8 9AG, United Kingdom, E-mail: S.M.Kazzazi@sms.ed.ac.uk, Mandankazzazi@gmail.com

Citation: Kazzazi SM, Kranioti EF (2017) Odontometric analysis of sexual dimorphism in permanent maxillary and mandibular molars. J Forensic Sci Criminol 5(1): 102. doi: 10.15744/2348-9804.5.102

Received Date: December 10, 2016 Accepted Date: February 25, 2017 Published Date: February 27, 2017

\begin{abstract}
In the field of human osteology, sex estimation is an important step in developing a biological profile. There are a number of methods that can be used to estimate the sex of human remains, varying from visual assessments to metric analysis of sexually dimorphic traits. Teeth are one of the most durable physical elements in the human body and thus can be very successfully used for this purpose. The present study investigates the utility of cervical measurements for sex estimation through discriminant analysis. The permanent molar teeth of 75 skeletons ( 28 females and 52 males) from the Hasanlu site in north-western Iran were studied. Cervical mesiodistal and buccolingual measurements were taken from both maxillary and mandibular first and second molars. Discriminant analysis was used to evaluate the accuracy of each diameter in assessing sex. The results showed that males had statistically larger teeth than females for maxillary and mandibular molars and cervical mesiodistal and buccolingual measurements $(\mathrm{P}<0.05)$. The range of classification rate was from $78.4 \%$ to $87.1 \%$ for the original and $78.4 \%$ to $85.5 \%$ for cross-validated data. The most dimorphic teeth were the maxillary and mandibular second molars, providing $87.1 \%$ and $86.1 \%$ correct classification rate respectively. The data generated from the present study suggested that cervical mesiodistal and buccolingual measurements of molar teeth can be useful and reliable for sex estimation in Iranian archaeological populations.
\end{abstract}

Keywords: Sex estimation; Cervical measurements; Hasanlu; Molars; Discriminant Function Analysis

\section{Introduction}

Odontometric studies of dentition have played an important role in human biological investigations, due to the strength of teeth and their resistance to post-mortem destruction and fragmentation. Many researchers have found that teeth present a high degree of sexual dimorphism [1-5]. The most widely used dimensions in sex estimation studies have been maximum mesiodistal and buccolingual crown measurements [1-5]. However, these measurements are difficult to obtain in worn teeth or crowns that are embedded in the jaw [6]. To solve this issue, alternative dental measurements were developed, including cervical mesiodistal and buccolingual measurements of teeth and crown, and cervical diagonal measurements of molars [6]. These measurements are less affected by wear and therefore can allow a larger dataset to be obtained, with a broader range of ages represented.

The present study examines the level of sexual dimorphism within the cervical measurements of permanent molars in an Iranian archaeological population, and evaluates the accuracy of these measurements in sex estimation. Since there are currently very few studies of sex estimation using odontometric data in either Iranian archaeological or modern populations the present study makes a significant contribution to the development of the standards of sex assessment in this population [7].

\section{Materials and Methods}

In total 282 permanent maxillary and mandibular teeth from 75 individuals ( 28 females and 52 males) from the Hasanlu collection were examined. Hasanlu is the largest and most important archaeological site in the Gadar River Valley in north-western Iran. This settlement was destroyed by fire during a battle, probably with Urartians, around 800 BC [8].

The skeletons of the Hasanlu individuals are stored in the University of Pennsylvania's Museum of Archaeology and Anthropology (UPM), in the United States. All the individuals used in this study, both males and females, were adults aged between 20 and 65 years. The sex of the skeletons was estimated using morphological features of the pelvis and skull due to their high level of sexual dimorphism and reliability [9-12]. 
Cervical mesiodistal and buccolingual measurements were taken using the Hillson-Fitzgerald Paleotech dental calliper with a calibration of $0.01 \mathrm{~mm}$. Each dimension was measured twice at a different time interval by one observer to assess intra-observer error (Table 1). The following measurements were used in this study:

- Mesiodistal cervical measurements were taken as the greatest mesiodistal dimension parallel to the occlusal and buccal surface measured in the cervical part of the tooth crown [13].

- Buccolingual cervical measurement was taken as the maximum measurement at the cement-enamel junction from buccal to lingual surface [6].

Dental measurements were taken from the left and right maxillary and mandibular first and second molars. To avoid the possibility of incorrect measurements, samples with caries, heavy calculus deposits, and hypoplastic defects along the cemento-enamel junction were excluded.

Statistical analysis was conducted using the SPSS 23 software. Bilateral asymmetry of right and left side in the entire sample was tested using a paired t-test. Technical error of measurements (TEM), relative technical error of measurements (rTEM), and the coefficient of reliability were used to assess intra-observer error. Using a one-way ANOVA the mean values of the measurements were compared between the sexes to determine if statistically significant differences existed. Percentages of sexual dimorphism were calculated according to Garn., et al. using the formula (male mean - female mean) × 100/2 [14,15].

Direct discriminant function analysis was used to create population specific formulae for the Iranian population. Discriminant function analysis (DFA) allows the examination of a set of independent variables to determine whether they can be used for the discrimination of a set of independent variables and provides the equations necessary for such discrimination [16]. A leave-oneout classification procedure was also used to demonstrate the accuracy rate of the original sample and the sample created by crossvalidation.

In total, four discriminant functions were performed:

- Function 1 Cervical diameters of maxillary first molars

- Function 2 Cervical diameters of mandibular first molars

- Function 3 Cervical diameters of maxillary second molars

- Function 4 Cervical diameters of mandibular second molars

\section{Results}

The results for intra-observer error variation are presented in Table 1, and indicate no significant differences in the two observations of each measurement. The mean rTEM for intra-observer error was $0.35 \%$, with a coefficient variation of 1 for all measurements. The variable with the highest rTEM value was the maxillary second molar $(0.45 \%)$.

Mean differences of all measurements between left and right maxillary and mandibular teeth were found to be statistically insignificant $(P>0.05)$. As a principle, we used measurements from the right maxillary and mandibular teeth for the analysis. In the case of a missing value from the right side, the left antimere was substituted.

\begin{tabular}{|c|c|c|c|c|c|c|c|c|c|}
\hline Measurements & $\mathbf{N}$ & \multicolumn{2}{|c|}{ Measurement 1 } & \multicolumn{2}{c|}{ Measurement 2 } & Diff & TEM & rTEM & R \\
\hline & & Mean & SD & Mean & SD & & & & \\
\hline Mesiodistal & & & & & & & & & \\
\hline UM1 & 48 & 7.66 & 0.56 & 7.66 & 0.55 & 0.00 & 0.03 & 0.39 & 1.00 \\
\hline LM1 & 31 & 8.85 & 0.52 & 8.86 & 0.53 & -0.01 & 0.02 & 0.26 & 1.00 \\
\hline UM2 & 42 & 7.55 & 0.70 & 7.56 & 0.71 & -0.01 & 0.03 & 0.45 & 1.00 \\
\hline LM2 & 22 & 9.01 & 0.65 & 9.02 & 0.64 & -0.02 & 0.03 & 0.36 & 1.00 \\
\hline Buccolingual & & & & & & & & & \\
\hline UM1 & 41 & 9.93 & 0.56 & 9.93 & 0.56 & -0.01 & 0.03 & 0.29 & 1.00 \\
\hline LM1 & 40 & 8.71 & 0.63 & 8.71 & 0.61 & 0.00 & 0.03 & 0.33 & 1.00 \\
\hline UM2 & 39 & 9.80 & 1.03 & 9.81 & 1.03 & -0.01 & 0.03 & 0.32 & 1.00 \\
\hline LM2 & 37 & 8.18 & 0.77 & 8.17 & 0.76 & 0.01 & 0.03 & 0.38 & 1.00 \\
\hline
\end{tabular}

$\mathrm{U}=$ Upper, $\mathrm{L}=$ Lower, $\mathrm{M}=$ Molar

Table 1: TEM and rTEM results evaluating intra-observer error in cervical tooth measurements

The results of the one-way ANOVA indicated that the differences between male and female mean values were significant for all measurements. Table 2 shows descriptive statistics, associated univariate F-ratio, and percentage of sexual dimorphism. . The highest F-value for the mesiodistal measurements was noted for mandibular second molar LM2 and for the buccolingual measurements for maxillary second molar. Yet, the most sexually dimorphic measurement was the mesiodistal diameter of the maxillary second 
molar with $14.14 \%$ of dimorphism, followed by the buccolingual diameter of the maxillary second molar and mandibular second molar, with $13.23 \%$ and $12.39 \%$ of dimorphism respectively (Table 2 ).

\begin{tabular}{|c|c|c|c|c|c|c|c|c|c|}
\hline Measurements & \multicolumn{3}{|c|}{ Females } & \multicolumn{3}{c|}{ Males } & SD\% & F ratio $^{\text {a }}$ & P-value $^{\text {-van }}$ \\
\hline n & Mea & n & Mean & SD & & & \\
\hline Mesiodistal & & & & & & & & & \\
\hline UM1 & 26 & 7.40 & 0.36 & 41 & 7.92 & 0.38 & 7.03 & 30.93 & 0.00 \\
\hline LM1 & 28 & 8.45 & 0.49 & 46 & 9.12 & 0.50 & 7.93 & 31.62 & 0.00 \\
\hline UM2 & 23 & 6.86 & 0.55 & 39 & 7.83 & 0.53 & 14.14 & 47.23 & 0.00 \\
\hline LM2 & 27 & 8.25 & 0.54 & 52 & 9.21 & 0.57 & 11.64 & 52.05 & 0.00 \\
\hline Buccolingual & & & & & & & & & \\
\hline UM1 & 26 & 9.52 & 0.46 & 41 & 10.29 & 0.59 & 8.09 & 31.98 & 0.00 \\
\hline LM1 & 28 & 8.29 & 0.47 & 46 & 8.96 & 0.56 & 8.08 & 27.88 & 0.00 \\
\hline UM2 & 23 & 9.07 & 0.53 & 39 & 10.27 & 0.60 & 13.23 & 64.35 & 0.00 \\
\hline LM2 & 27 & 7.67 & 0.55 & 52 & 8.62 & 0.52 & 12.39 & 53.64 & 0.00 \\
\hline
\end{tabular}

$\mathrm{U}=$ Upper, $\mathrm{L}=$ Lower, $\mathrm{I}=$ Incisor, $\mathrm{C}=$ Canine, $\mathrm{P}=$ Premolar, $\mathrm{M}=$ Molar.

${ }^{a}$ All variables were significant at $P<0.001$.

Table 2: Descriptive statistics, \%SD (sexual dimorphism), and F ratio of the differences between the sexes

The results of the direct discriminant function analysis are shown in Table 3. This table includes the tooth variables that entered the direct analysis, the coefficient indicating the relative contribution of each dimension, degree of freedom (df), and the F values of each variable and the constant for each formula For example Function 1 uses the dimensions of the first maxillary molar to estimate sex of an unknown individual as follows: $\mathrm{F} 1=1.46$ * UM1MD +1.01 * UM1BL-21.92

If $\mathrm{F} 1>\mathrm{O}$ the tooth belongs to a male while if $\mathrm{F} 1<0$ it belongs to a female.

\begin{tabular}{|c|c|c|c|c|c|c|c|}
\hline \multirow[t]{2}{*}{$\begin{array}{l}\text { Variables } \\
\text { entered }^{a}\end{array}$} & \multirow[t]{2}{*}{$\begin{array}{c}\text { Wilks } \\
\text { lambda }\end{array}$} & \multirow[t]{2}{*}{ Exact $\mathrm{F}$} & \multirow[t]{2}{*}{ df } & \multirow[t]{2}{*}{$\begin{array}{c}\text { Raw } \\
\text { coefficient }\end{array}$} & \multicolumn{2}{|c|}{$\begin{array}{c}\text { Classification } \\
\text { function }\end{array}$} & \multirow[t]{2}{*}{ p-value } \\
\hline & & & & & Male & Female & \\
\hline \multicolumn{8}{|l|}{ F1: UM1 } \\
\hline MD & 0.68 & 30.93 & 1,65 & 1.46 & & & 0.00 \\
\hline BL & 0.67 & 31.98 & 1,65 & 1.01 & & & 0.00 \\
\hline Constant & & & & -21.92 & & & \\
\hline Centroid & & & & & 0.61 & -0.96 & \\
\hline \multicolumn{8}{|l|}{ F2: LM1 } \\
\hline MD & 0.70 & 31.62 & 1,72 & 1.27 & & & 0.00 \\
\hline BL & 0.72 & 27.88 & 1,72 & 0.93 & & & 0.00 \\
\hline Constant & & & & -19.36 & & & \\
\hline Centroid & & & & & 0.56 & -0.92 & \\
\hline \multicolumn{8}{|l|}{ F3: UM2 } \\
\hline MD & 0.56 & 47.23 & 1,60 & 0.89 & & & 0.00 \\
\hline $\mathrm{BL}$ & 0.48 & 64.35 & 1,60 & 1.22 & & & 0.00 \\
\hline Constant & & & & -18.67 & & & \\
\hline Centroid & & & & & 0.87 & -1.48 & \\
\hline \multicolumn{8}{|l|}{ F4: LM2 } \\
\hline MD & 0.60 & 52.05 & 1,77 & 1.02 & & & 0.00 \\
\hline BL & 0.59 & 53.64 & 1,77 & 1.09 & & & 0.00 \\
\hline Constant & & & & -18.07 & & & \\
\hline Centroid & & & & & 0.69 & -1.33 & \\
\hline
\end{tabular}

$\mathrm{MD}=$ Mesiodistal, $\mathrm{BL}=$ Buccolingual, $\mathrm{U}=$ Upper, $\mathrm{L}=$ Lower, $\mathrm{M}=$ Molar.

Table 3: Direct discriminant function analysis of cervical mesiodistal and buccolingual measurements of all teeth

Table 4 presents the classification accuracy of all functions. The best formula was found to be F3 for the maxillary second molar (87.1\%), followed by F4 for the mandibular second molar (86.1\%) and F1 for the maxillary first molar (82.1\%). The mandibular first molar provided the lowest accuracy rate of 78.4\%. Accuracy ranged from $87-90.4 \%$ in males and $64.3-82.6 \%$ in females and in most occasions males were classified more accurately compared to females Cross validation accuracy was close to the original classification accuracy in all cases (Table 4). 


\begin{tabular}{|c|c|c|c|c|c|c|c|}
\hline \multirow{2}{*}{ Functions } & \multicolumn{5}{|c|}{ Predicted Group Membership } & N \\
\hline & \multicolumn{3}{|c|}{ Original \% } & \multicolumn{3}{c|}{ Cross-validated \% } & \\
\hline & Male & Female & Total & Male & Female & Total & \\
\hline F1: UM1 & 90.2 & 69.2 & 82.1 & 90.2 & 69.2 & 82.1 & 67 \\
\hline F2: LM1 & 87.0 & 64.3 & 78.4 & 87.0 & 64.3 & 78.4 & 74 \\
\hline F3: UM2 & 89.7 & 82.6 & 87.1 & 87.2 & 82.6 & 85.5 & 62 \\
\hline F4: LM2 & 90.4 & 77.8 & 86.1 & 90.4 & 70.4 & 83.5 & 79 \\
\hline
\end{tabular}

$\mathrm{MD}=$ Mesiodistal, $\mathrm{BL}=$ Buccolingual, $\mathrm{U}=$ Upper, $\mathrm{L}=$ Lower, $\mathrm{M}=$ Molar

Table 4: Classification accuracy of original and cross validated samples

\section{Discussion}

The correct identification of sex from skeletal remains is one of the main challenges in forensic anthropology and osteoarchaeology. Dental sexual dimorphism has long been acknowledged as a reliable biological feature in this respect, and studies have demonstrated that dental dimensions can be used to accurately assess the sex of skeletal remains in different populations [1-5,17-24]. The present study is one of few reference studies for sex estimation using odontometric data in Iranian archaeological populations [7].

This study used cervical mesiodistal and buccolingual measurements of permanent maxillary and mandibular first and second molars for sex estimation. All variables analysed here presented statistically significant differences between males and females $(P$ $<0.001)$. A comparison between the two sexes showed that the classification accuracy of all functions was higher for males. This result is in agreement with other studies on molar odontometrics [13,17-22].

The greatest difference in percentage of sexual dimorphism was observed in the maxillary second molar. There is little comparative data against which the amount of sexual dimorphism in cervical measurements can be compared. Tuttösí and Cardoso are the only authors that provide percentage of sexual dimorphism for cervical tooth measurements in other archaeological samples (Pender Island) [23]. The percentage of sexual dimorphism for the maxillary second molar in our study was $14.14 \%$ (mesiodistal) and 13.23\% (buccolingual), which is higher than in the Tuttösí and Cardoso study (13.06\% mesiodistal and 8.14\% buccolingual) [23]. Yet, other studies on crown and diagonal measurements of molars report different results. For example, Prabhu and Acharya report the mandibular first molar as the most sexually dimorphic tooth in Indian populations, while Işcan and Kedici observe the highest degree of sexual dimorphism in the maxillary first molar of Turkish populations [5,24]. A recent study by Peckmann., et al. on African American populations also reports the maxillary third molar as the most sexually dimorphic tooth [22]. These differences can be attributed to genetic and/or environmental influences in the expression of sexual dimorphism of the human dentition [20].

Discriminant function analysis gave high classification accuracy for sex estimation (Table 4). In all functions the accuracy rate was $>80 \%$, except function 4 (78.4\%). A comparison between the maxillary and mandibular molars showed that maxillary molars were more dimorphic than mandibular molars. Zorba., et al. also reported similar results for diagonal measurements of molar teeth in a modern Greek population [20]. The highest rate of accuracy was observed in the maxillary second molar (87.1\%), followed by the mandibular second molar (86.1\%). These results are in accordance with previous studies on crown and diagonal measurements of molars $[20,23,25]$.

A comparison between the two sexes showed that the classification accuracy of all functions was higher for males than for females for both original and cross-validated data. This means that females have the greatest disparity of teeth size and can more often be misclassified as male. This is in contrast to the studies by Isscan and Kedici and Peckmann., et al. on crown mesiodistal, buccolingual, and diagonal measurements, which reported higher classification accuracy in females [5,22]. This may show that there is a lower degree of sexual dimorphism in males for crown mesiodistal, buccolingual, and diagonal measurements, but not in the case of cervical mesiodistal and buccolingual measurements. This is consistent with the studies by Tuttösí and Cardoso and Viciano., et al. on cervical mesiodistal and buccolingual measurements $[17,18,23]$.

\section{Conclusion}

In conclusion, sex estimation using cervical measurements of molars in an Iranian archaeological population has proven to be highly accurate for both original and cross-validated data. These measurements can be very useful in cases of fragmentary remains, and also in cases where other dental measurements such as mesiodistal and buccolingual crown measurements cannot be taken due to the presence of dental wear or other pathology. The present study in particular is important for the application to unknown skeletal remains from Iran around the same period (Iron Age); especially considering that molars are more likely to survive harsh taphonomic conditions than any other skeletal element $[13,26]$. There is ample justification for expanding this study in other archaeological populations with poor preservation in an effort to reconstruct paleodemography and population history.

\section{Acknowledgements}

We would like to thank Dr. Janet Monge for providing us access to the Hasanlu skeletal collections at the University of Pennsylvania Museum of Archaeology and Anthropology. We would also like to thank Dr. Linda Fibiger for her valuable contribution and support during the examination process. 


\section{References}

1. Acharya AB, Mainali S (2007) Univariate sex dimorphism in Nepalese dentition and the use of discriminant function in gender assessment. Forensic Sci Int 173: 47-56.

2. Khamis MF, Taylor JA, Malik SN, Townsend GC (2014) Odontometric sex variation in Malaysians with application to sex prediction. Forensic Sci Int $234: 183$.

3. Black TK (1978) Sexual dimorphism in the tooth-crown diameters of the deciduous teeth. Am J Phys Anthropol 48: 77-82.

4. Angadi PV, Hwmani S, Suddendra, P, Acharya A (2013) Analysis of odontometric sexual dimorphism and sex assessment accuracy of the decisous teeth. Am J Phys Anthropol 48: 77-82.

5. Işcan MY, Kedici PS (2003) Sexual variation in buccolingual dimensions in Turkish dentition. Forensic Sci Int 137: 160-4.

6. Hillson S, FitzGerald C, Flinn H (2005) Alternative dental measurements: proposals and relationships with other measurements. Am J Phys Anthropol 126: 413-26.

7. Kazzazi SM, Kranioti EF (2016) Sex estimation using cervical dental measurements in an archaeological population from Iran. Archaeol Anthropol Sci 1-10.

8. Dyson RH (1965) Problems of protohistoric Iran as seen from Hasanlu. JNES 24: 193-217.

9. Phenice TW (1969) A newly developed visual method of sexing in the Os pubis. Am J Phys Anthropol 30: 297-301.

10. Walker PL (2008) Sexing skulls using discriminant function analysis of visually assessed traits. Am J Phys Anthropol 136: 39-50.

11. Bruzek J (2002) A method for visual determination of sex, using the human hip bone. Am J Phys Anthropol. 117: 157-68.

12. Williams BA, Rogers TA (2006) Evaluating the accuracy and precision of cranial morphological traits for sex determination. J Forensic Sci. 51: 729-35.

13. Vodanovic M, Demo Z, Njemirovskij V, Keros J, Brkic H (2007) Odontometrics: a useful method for sex determination in an archaeological skeletal population? J Archaeol Sci 34: 905-13.

14. Ulijaszek SJ, Kerr A D (1999) Anthropometric measurement error and the assessment of nutritional status. Br J Nutr 82: 165-77.

15. Garn SM, Lewis AB, Swindler DR, Kerewsky RS (1967) Genetic control of sexual dimorphism in tooth size. J Dent Res 46: 963-72.

16. Hill T, Lewicki P (2006) Statistics: methods and applications: a comprehensive reference for science, industry, and data mining. Tulsa: Statsoft Inc.

17. Viciano J, Aleman I, D’Anastasio R, Capasso L, Botella MC (2011) Odontometric sex discrimination in the Herculaneum sample (79 AD, Naples, Italy), with application to juveniles. Am J Phys Anthropol 145: 97-106.

18. Viciano J, Lopez-Lazaro S, Aleman I (2013) Sex estimation based on deciduous and permanent dentition in a contemporary Spanish population. Am J Phys Anthropol 152: 31-43.

19. Zorba E, Moraitis K, Manolis SK (2011) Sexual dimorphism in permanent teeth of modern Greeks. Forensic Sci Int 210: 74-81.

20. Zorba E, Moraitis K, Eliopoulos C, Spiliopoulou C (2012) Sex determination in modern Greeks using diagonal measurements of molar teeth. Forensic Sci Int 217: 19-26.

21. Zorba E, Spiliopoulou C, Moraitis K (2013) Evaluation of the accuracy of different molar teeth measurements in assessing sex. Forensic Sci Med Pathol 9, 13-23. 22. Peckmann TR, Meek S, Dilkie N, Mussett M (2015) Sex estimation using diagonal diameter measurements of molar teeth in African American populations. J Forensic Leg Med 36: 70-80.

23. Tuttösí P, Cardoso HFV (2015) An assessment of sexual dimorphism and sex estimation using cervical dental measurements in a Northwest coast archaeological sample. J Archaeol Sci: Report 3: 306-12.

24. Prabhu S, Acharya AB (2009) Odontometric sex assessment in Indians. Forensic Sci Int 192: 129e1-5.

25. Viciano J, D’Anastasio R, Capasso L (2015) Odontometric sex estimation on three populations of the Iron Age from Abruzzo region (central-southern Italy). Arch Oral Biol. 60: 100-15.

26. Andersen L, Juhl M, Solheim T, Borrman H (1995) Odontological identification of fire victims—potentialities and limitations. Int J Legal Med 107: 229-34.

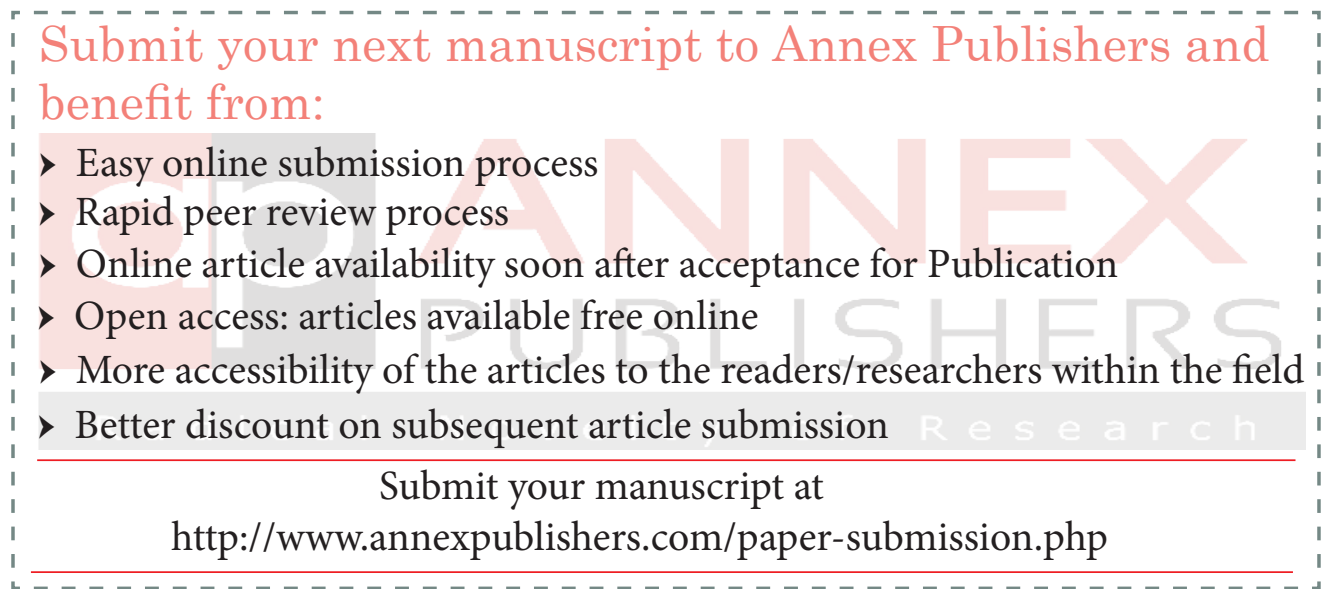

